\title{
Societal life cycle assessment-could you repeat the question?
}

\author{
Thomas E. Swarr
}

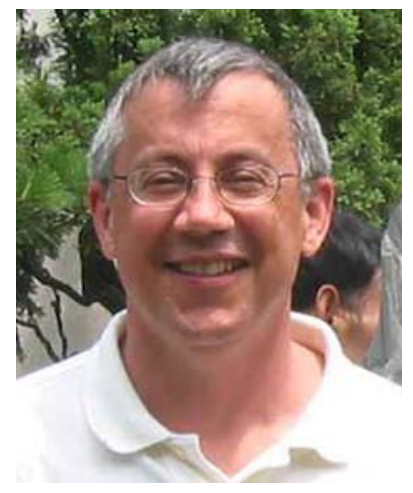

\section{Can social impacts be quantified?}

It is generally accepted that life cycle assessment (LCA) is the predominant methodology for evaluating the environmental impacts of a product system. It is also recognized that it is important to integrate the three pillars of sustainability-ecology, economics, and social equity-using the same functional unit and system boundaries and preferably in quantitative terms in order to evaluate whether alternative product systems are "more or less sustainable." (Klöpffer 2003, 2008; Reap

Tom Swarr belongs to the panel of Subject Editors for Int J Life Cycle Assess and is responsible for the area of "Societal Life Cycle Assessment."

T. E. Swarr $(\bowtie)$

Sustainability by Design, LLC,

8 Shultas Pl,

Hartford, CT 06114, USA

e-mail: tomswarr@SustainabilitybyDesign.org et al. 2008b). Numerous methodological challenges might lead us to question the feasibility of societal life cycle assessment (SLCA), even though a United Nations Environment Programme (UNEP) work group determined there were no fundamental barriers (Grießhammer et al. 2006). Social concerns are highly diverse and have spawned more than 200 indicators that are weighted differently by different interest groups (Hunkeler and Rebitzer 2005). Many social indicators either describe impacts or behaviors that predispose a specific impact and not fundamental behaviors that would parallel flows in LCA (Joergensen et al. 2008). It has also been argued that social impacts are not directly related to process flows, but rather to the way a particular company interacts with its stakeholders (Dreyer et al. 2006; Hauschild et al. 2008). This would emphasize the need for company- and location-specific data and further complicate allocating impacts to specific products. Many indicators are difficult to quantify and can be assessed only in qualitative terms. The additional steps of data collection and modeling necessary to link midpoint attributes to specific damages can introduce large uncertainties. The variability of externality estimates for electric power generation caused by methodological uncertainties is comparable to that caused by alternative technologies as different as solar and coal, suggesting that the approach can only give unambiguous answers when the choice is so obvious that no analysis is necessary (Lenzen 2006).

Einstein warned, "Not everything that can be counted counts, and not everything that counts can be counted." Klöpffer $(2003,2008)$ highlighted that the goal of SLCA or life cycle sustainability assessments is to provide reliable results that can inform decisions (and facilitate learning) at multiple levels of society. People do not need - or often use - detailed knowledge of impact pathways or damage 
costs to make judgments about the relative risks and benefits of alternative products or technologies (Lenzen 2006). Arrow's Impossibility Theorem states that collective choice cannot be both logical and fair (Arrow 1963). It is probably more important that SLCA defines a rational process that will be perceived as fair than yield a quantitatively unambiguous answer. The number of potential considerations relative to the effectiveness or sustainability of organizational actions makes it imperative to focus on the select few most salient issues. In a world where management attention is the scarce resource, more detailed information could be an expensive luxury that only serves to distract focus from the priority concerns most important to affected stakeholders (Simon 1978).

"Complexity is deep in the nature of things, and discovering tolerable approximation procedures and heuristics that permit huge spaces to be searched selectively lies at the heart of intelligence... (p. 12)."

Asking the right question will often be more important than calculating the right answer.

\section{What is the question and who is asking?}

To be a useful tool, SLCA must adapt to the actual context of the relevant decision-maker (Hauschild et al. 2008). All significant impacts must be considered, and the link between an organization's actions and the impact or damage to affected stakeholders should be clearly defined and relatively certain (Dreyer et al. 2006). Finally, required inventory information, detailed procedures for measuring impacts, and some agreement on how to value or weight different categories of impacts all need to be balanced according to the requirements of the decision-maker (Joergensen et al. 2008). At the same time, there needs to be some consistency or standardization to build credibility with impacted stakeholders and to avoid biasing the analysis with assumptions tailored to the desired answer. The World Business Council for Sustainable Development project on sustainable consumption suggests three broad classes of decisions where SLCA can help guide business toward more sustainable product systems (2008):

- Innovation - business processes for the development of new and improved products, services, and businesses,

- Choice influencing - the use of marketing and awareness raising campaigns to encourage consumers to choose and use products more sustainably, and

- Choice editing - the removal of unsustainable products and services from the marketplace.

Each class of decisions will impose a set of minimum requirements for which stakeholders must be engaged, types of information required, and criteria for evaluating the quality of the decision. It is also important to recognize that each of these questions can be asked by business looking out on society or by society looking in on business.

Innovation is predominantly an internal business process. The business perspective would rely on mostly quantitative measures, and the quality of their decisions will ultimately be judged by the financial success of the company. Relevant stakeholders would primarily be those directly affected by the financial transactions associated with building, selling, servicing, and retiring the product. Externalities or indirectly affected stakeholders would be included only when those issues could be integrated into the product offering and the resulting value captured based on current financial structures. However, social acceptance of technology innovations is a requirement for financial success. Innovations are driven by consumer demand for new gadgets with expanded functionality, and consumers do not always use new products as intended by designers. The way in which the product is adopted and embedded in existing social and technical structures will to an extent determine the resulting impacts (Rohracher 2003). Viewing innovation from the perspective of the end-user could lead to more successful and sustainable innovations.

Choice influencing should be a two-way conversation between business and society (civil and governmental) to develop a common understanding of what constitutes a sustainable product or lifestyle. The approach would necessarily be more inclusive and qualitative. Business is striving to assure consumers understand and value the sustainable attributes of their offerings. Consumers are striving to make companies aware of the invisible damages caused by products or the losses that are indirect, hard to measure, or result from a series of compounding impacts (Turner et al. 2008). The quality of decisions will be judged in terms of the credibility and relevance of information, and ultimately, by public support for company sustainability initiatives. The challenges of developing a generally accepted list of social indicators, selecting those most relevant to the decision at hand, and agreeing on the data and procedures used to measure and communicate performance will be crucial.

Not all problems will be amenable to solving through voluntary corporate initiatives or market-based solutions. There will always be indirect damages caused by the actions of others (Turner et al. 2008). All products benefit one group of stakeholders at the expense of other groups. At some point, the overall benefit to society simply does not justify the damage caused. The political process used to decide a product is unsustainable must be inclusive and verify that all interested stakeholders have had a voice. The information needs are complex. Data must be gathered in terms meaningful to affected stakeholders, but processed in some form that is compatible with legal and regulatory 
procedures. The quality of a decision will be judged on its perceived fairness and consistency. Establishing a causal link from company action to eventual damages that is accepted by affected stakeholders as reasonable and likely is a key challenge to drive action and inform sound public policy. Choice editing is predominantly a sociopolitical process to impose rules on business, but would be equally valuable from the business perspective as a risk management process.

\section{Key questions for a practical SLCA methodology}

A reasonable goal for SLCA is to define a reliable process that will help decision-makers effectively consider the interests of stakeholders outside their direct sphere of interest, e.g., other product systems, other geographic regions, future generations, etc., and make functional choices that move toward mutually acceptable objectives (Musters et al. 1998). The critical issues for SLCA are very similar to those identified in a recent review of unresolved problems in LCA methods (Box 1). The specific requirements of the three decision classes discussed above can help guide researchers toward methodological approaches that give approximately right or "good enough" solutions for the right questions. Researchers focused on SLCA will need to consider which of these problems are most relevant to consideration of social impacts, and conversely, how can consideration of social impacts contribute to methodological advances relevant to LCA and life cycle costing (LCC)?

Box 1 LCA problems by phase (Reap et al. 2008a, b)

\begin{tabular}{ll}
\hline Phase & Problem \\
\hline Goal and scope definition & Functional unit definition \\
& Boundary selection \\
& Social and economic impacts \\
& Alternative scenario consideration \\
& Allocation \\
Cutoff criteria & Local technical uniqueness \\
Life cycle inventory & Impact category and methodology \\
& selection \\
Life cycle impact & Spatial variation \\
assessment & Local environment uniqueness \\
& Dynamics of environment \\
& Time horizons \\
& Weighting and valuation \\
& Uncertainty in decision process \\
Life cycle interpretation & Data availability and quality \\
\hline
\end{tabular}

Social impacts are at the very root of the problem of defining a functional unit and delineating system boundaries.
Life cycle methods attempt to define a functional unit that enables different product systems to be compared on an equal basis. Companies, however, continually innovate their product offerings to build in new features or functionalities that differentiate their products to achieve a competitive advantage and avoid competing strictly on the basis of cost and delivery. Various customer support features and services are used to create switching costs and build brand loyalty. The customers' emotional connection is linked to the social benefits and costs of the product. Thus, the economy grows by absorbing more and more features of the social and natural worlds as resources to be mobilized for competitive advantage (Anderson 2006). Externalities are the zone of conflict, and deciding where to draw the boundary is the fundamental question for sustainability, and one that will continue to evolve over time. What is the functional unit of an iPhone with hundreds of apps? Cell phone technology can improve the profitability of impoverished farmers in developing economies or illicit drug dealers in urban slums. The technology has had wide ranging impacts on how people communicate with each other that likely go far beyond anything imagined by the designers of the early phones. Any delineation of the system boundaries will be tentative, based on current assumptions of relevant impacts and affected stakeholders (Musters et al. 1998). Given this complexity, a practical suggestion was that product use be modeled based on established product category definitions (Joergensen et al. 2008). Research in support of integrated product policy (IPP) to identify and prioritize which product categories link to the most significant impacts could provide useful insights (Tukker and Jansen 2006). Another promising suggestion was to analyze the environmental inventory to determine the "controls over, organization of and actions in the life cycle" to identify impacted social, cultural, and political structures (Hutchins and Sutherland 2008). Structuring LCA and LCC studies with consistent boundaries is crucial to obtaining technically valid results. However, evaluating the zone of conflict at the defined system boundary is a social process that will ultimately determine if the results are accepted and acted upon. It will be equally important to effectively communicate the criteria for whom and what was included in and excluded from the assessment.

Another critical question for SLCA is whether the impact categories can be related to the same processbased inventory data used for LCA and LCC. If social impacts are not directly related to the process flows, then there will need to be well-defined rules for allocating impacts to specific product systems. Dreyer et al. (2006) propose determining a share factor to aggregate the weights of each company's social profile along the product chain. Norris (2006) proposes a method for life cycle attribute assessment to summarize attributes of processes across a 
company supply chain. Klöpffer $(2003,2008)$ argued that, for meaningful product sustainability assessments, all impacts must be quantitatively linked to a functional unit. Weidema (2006) draws from cost-benefit analysis and LCA to propose a comprehensive set of indicators and provide examples of impact chains, linking the social inventory indicators to impacts on human well-being and productivity. Hunkeler (2006) decomposes unit processes of the life cycle inventory into regional labor hours, and then evaluates social impacts based on the ability to use the labor income to obtain basic needs, such as food and housing. Resolving these questions is a necessary step in defining and validating social indicators.

A third set of questions relates to the inherent disconnect between the global logic of product value chains and place-based sustainability assessments. Spatial variation of environmental aspects and resulting impacts has been shown to cause several orders of magnitude of variation (Reap et al. 2008b). Even if sitegeneric data were used, SLCA would have to allow for location-specific valuation to account for the different priorities of different communities. Here again, research for IPP may offer valuable insights about the information architecture required to support decision-making regarding the technical systems (Tukker et al. 2006). Site-specific models would likely be too complex for product designers, but it may be possible to use national and regional models as calibration standards for simpler design support tools (Reap et al. 2008b). It seems likely that different locations will not only value chosen impact categories differently but actually focus on completely different impact categories. Impact categories can be defined based on a combination of top-down and bottom-up approaches. Bottom-up identification focuses on the issues relevant to the specific decision context-industry sector, product category, and geographic region. Top-down identification focuses on universal values as embodied in international agreements, such as the Universal Declaration of Human Rights, which establish minimum requirements that must be satisfied in all cases (Dreyer et al. 2006). Combining these approaches into a coherent system that can be practically applied will be yet another challenge.

\section{Call for papers}

The UNEP feasibility study identified a set of further steps to promote the development and practical use of SLCA that also serve as a useful call for papers (Box 2). The discussion above can provide further guidance for future work to resolve some of the critical questions and to demonstrate how SLCA can be used to inform decisions at multiple levels of society.
Box 2 Further steps to develop SLCA (Grießhammer et al. 2006)

- Conduct case studies

- Establish a list of generally accepted social indicators

- Define and characterize the individual indicators

- Check and improve existing databases for upstream chains

- Agree on a way of providing information

- Compose a code of practice

It is advisable to start with big questions, where even crude approximations can provide useful insights. Food, energy, transportation, and housing have been shown to largely determine our ecological footprint. Product offerings in these sectors address our basic needs, but also in richer economies compete on the basis of psychological, esthetic, or experiential wants (Anderson 2006). Case studies in these sectors could explore the definition of functional unit and selection of system boundaries. Retrospective studies of past technological innovations could provide useful insights on missed signals (from failed innovations) or key elements of a code of practice (from successful innovations). Exploratory case studies of controversial innovations, such as digitized medical records, GMO foods, or nanotechnology could assess the value of SLCA to inform innovation decision processes.

The broader overview of the case studies could be productively supplemented with more detailed studies of social indicators. These would likely benefit from the topdown and bottom-up approach discussed above. The bottom-up approach focuses on the needs of the impacted stakeholders and relevance to the decision under consideration. Top-down approaches focus on the basic requirements that establish some minimum level of performance for standardization through international agreements industry codes of practice, etc. The details of how to define and measure each indicator, availability and quality of necessary data, relation to process based inventories, and suitability of the indicator for decision-making at various levels are all worthy topics. The use of common process inventory data and models offers obvious synergies and would facilitate the use of life cycle methods in decisionmaking (Hunkeler 2006; Hunkeler and Rebitzer 2005). Verifying that social indicators can be linked to the functional unit through the same life cycle inventory data structures would be a valuable contribution. Hunkeler's (2006) approach of using employment hours per inventory element makes central the assessment of how effectively the market economy improves our well-being, and thus merits further work. It would be interesting to explore the implications of different skill levels of employment and the distribution of economic benefits between labor and capital, 
which are important questions for creating sustainable livelihoods.

Combining the indicators and lessons from case studies to sketch out a code of practice is the ultimate goal. Critique of the proposed decision classes as an organization principle for the code would be welcome along with suggestions of other schema. Exploration of the choice editing decisions mentioned above could help refine the definition and goals of sustainable consumption and production. It would seem that some unsustainable impacts cut across so many product categories, e.g., toxic chemicals, that a product-based analysis may not be helpful. In other cases, products are clearly linked to damages, e.g., sin products such as alcohol and tobacco. Papers evaluating the usefulness of SLCA in public policy would be valuable contributions. It is important to remember that sustainable products will not necessarily yield sustainable communities. If our goal is informed decisions at multiple levels of society, it will be necessary to link the global- and hazardbased perspective of product chains to regional- and riskbased perspective of communities. The specific impacts in a community will depend on the particular mix of product chains that happen to flow through that area. It is beyond the scope of any single company to consider these complex interactions within their product design choices. At the same time, companies will be interested in validating that their initiatives have in fact produced the intended benefits. Data architectures that permit efficient sharing of data between decision models for various scales would help increase the value of SLCA to both private and public decision-makers. Research in supply chain management or regional planning might provide useful insights.

This brief list is certainly not exhaustive. SLCA offers a rich landscape of potential research topics. It would be wise to conclude with a cautionary note from Hunkeler and Rebitzer (2005) that "(a)dditional levels of sophistication, and new models, should not neglect the needs and reality of decision making." We need simple but not simplistic approaches to scan a complex world and focus on those challenges that will best move us toward more sustainable business models (Klöpffer 2003). Einstein advised, "Everything should be made as simple as possible, but not one bit simpler." Perhaps a useful first step is to identify the important questions we are trying to answer with SLCA, clarify what we do not know that we need to know to answer those questions, and recognize that any sustainability assessment will be a journey of learning.

Acknowledgement I would like to acknowledge David Hunkeler's previous work in launching the subject area of societal life cycle analysis and for his contributions toward advancing the state-of-theart. I owe a personal debt to David as a mentor in helping me develop and refine my understanding of this challenging topic. I have learned much from our discussions and deeply appreciate his patience in responding to my many questions and frequent requests to review a preliminary draft of some idea or thought.

\section{References}

Anderson V (2006) Turning economics inside out. Int J Green Econ 1 $(1 / 2): 11-22$

Arrow KJ (1963) Social choice and individual values, 2nd edn. Yale University Press, New Haven, CT

Dreyer LC, Hauschild MZ, Schierbeck J (2006) A framework for social life cycle impact assessment. Int J Life Cycle Assess 11(2):88-97

Grießhammer R, Benoît C, Dreyer LC, Flysjö A, Manhart A, Mazjin B (2006) Feasibility study: integration of social aspects into LCA. Available at http://fr1.estis.net/builder/includes/page.asp?site= lcinit\&page id=D45A9A8F-10FA-4501-BF93-FB9AEAE4D163. Accessed 20 January 2009

Hauschild MZ, Dreyer LC, Joergensen A (2008) Assessing social impacts in a life cycle perspective-lessons learned. CIRP Annals-Manufacturing Technology 57:21-24

Hunkeler D (2006) Societal LCA methodology and case study. Int J Life Cycle Assess 11(6):371-382

Hunkeler D, Rebitzer G (2005) The future of life cycle assessment. Int J Life Cycle Assess 10(5):305-308

Hutchins MJ, Sutherland JW (2008) An exploration of measures of social sustainability and their application to supply chain decisions. J Clean Prod 16:1688-1698

Joergensen A, Le Bocq A, Nazarkina L, Hauschild MZ (2008) Methodologies for social life cycle assessment. Int J Life Cycle Assess 13(2):96-103

Klöpffer W (2003) Life-cycle based methods for sustainable product development. Int J Life Cycle Assess 8(3):157-159

Klöpffer W (2008) Life cycle sustainability assessment of products. Int J Life Cycle Assess 13(2):89-94

Lenzen M (2006) Uncertainty in impact and externality assessments: implications for decision-making. Int $\mathrm{J}$ Life Cycle Assess 11 (3):189-199

Musters CJM, de Graaf HJ, ter Keurs WJ (1998) Defining socioenvironmental systems for sustainable development. Ecol Econ $26: 243-258$

Norris GA (2006) Social impacts in product life cycles: towards life cycle attribute assessment. Int J Life Cycle Assess 11(1):97-104

Reap J, Roman F, Duncan S, Bras B (2008a) A survey of unresolved problems in life cycle assessment. Part 1: goal and scope and inventory analysis. Int J Life Cycle Assess 13(4):290-300

Reap J, Roman F, Duncan S, Bras B (2008b) A survey of unresolved problems in life cycle assessment. Part 2: impact assessment and interpretation. Int J Life Cycle Assess 13(5):374-388

Rohracher H (2003) The role of users in the social shaping of environmental technologies. Innovation 16(2):177-192

Simon HA (1978) Rationality as a process and product of thought. Am Econ Rev 68(2):1-16

Tukker A, Jansen B (2006) Environmental impacts of products: a detailed review of studies. J Ind Ecol 10(3):159-182

Tukker A, Eder P, Suh S (2006) Environmental impacts of products: policy relevant information and data challenges. J Ind Ecol 10(3):183-198

Turner NJ, Gregory R, Brooks C, Failing L, Satterfield T (2008) From invisibility to transparency: identifying the implications. Ecol Soc 13(2), article 7. Available at http://www.ecologyandsociety. org/vol13/iss $2 /$ art7/

WBCSD (2008) Sustainable consumption facts and trends: from a business perspective. World Business Council for Sustainable Development, Geneva, Switzerland

Weidema B (2006) The integration of economic and social aspects in life cycle impact assessment. Int J Life Cycle Assess 11(1):89-96 